\title{
PERSPECTIVAS EN LA FILOSOFÍA Y TEOLOGÍA DE LA LIBERACIÓN E HISTORIA DE LAS IDEAS: PROPUESTAS PARA PROPICIAR UNA EDUCACIÓN DESCOLONIAL
}

\author{
CARLOS FRANCISCO BAUER ${ }^{1}$
}

RESUMEN: Este trabajo propone un recorrido pedagógico, por medio de una serie de propuestas que abordan elaboraciones críticas de pensadores des-coloniales y liberacionistas, que han contribuido a marcar el rumbo del nuevo camino que seguirán las ciencias sociales en Abya Yala (América Latina), como fuentes metodológicas y epistémicas desde donde podemos deconstruir los proyectos de educación colonial y, a la vez, avanzar en la proposición de una educación y una práctica para la liberación de dichas estructuras de dominación. Una de las principales funciones teórico-práctica de la filosofía de la liberación es propiciar una educación para la descolonización y la liberación cultural, epistémica, política, económica, ecológica, estética, espiritual de América.

PALABRAS CLAVES: Filosofía de la liberación, historia de las ideas, descolonialidad, sujeto, mestizaje.

ABSTRACT: This work proposes a pedagogical journey, through a series of proposals that approach critical elaborations of des-colonial and liberationist thinkers, that have marked the course of the new path that the social sciences will follow in Abya Yala (Latin America), as methodological sources and epistemic from which we can deconstruct the projects of colonial education and, at the same time, advance in the proposition of an education and a practice for the liberation of said structures of domination. One of the main theoretical-practical functions of the philosophy of liberation is to promote education for the decolonization and cultural, epistemic, political, economic, ecological, esthetic, spiritual liberation of America.

KEYWORDS: Philosophy of liberation, history of ideas, decoloniality, subject, miscegenation.

\section{Arturo Andrés Roig sobre la historia del nosotros y de lo nuestro ${ }^{2}$}

El sujeto latinoamericano no puede ser redefinido desde el sujeto opresor, ya que este sujeto desde la historia de su sí mismo ha negado rotundamente nuestra historia. Esto no está expresado de manera liviana, ya que lo que ha sucedido de manera fáctica, a lo largo de la

\footnotetext{
${ }^{1}$ Professor de História pela Universidad Nacional de Córdoba (UNC). Professor de Filosofia pela Universidade Federal da Integração Latino-americana (UNILA). Doutor em Filosofia pela Universidad Nacional de Córdoba (UNC). E-mail: carlosfrancisco120@yahoo.com.ar.

2 Arturo Andrés Roig fue un filósofo e historiador argentino nacido en Mendoza y graduado en la Universidad Nacional de Cuyo. En un principio integraba el movimiento de la filosofía de la liberación y luego pasó a ser parte fundamental de la corriente de historia de las ideas.
} 
historia, es la definición de lo que el sujeto latinoamericano debe ser desde las estructuras que el sujeto opresor ha impuesto. Cuando el sujeto latinoamericano ensayó, en diferentes regiones, proyectos de identidad propias, estos fueron castrados. El sujeto latinoamericano tampoco puede ser redefinido desde una especie de trascendencia abstracta, sino que dicho sujeto histórico debe saber y poder ejercer un proceso pedagógico de resemantización inmanente, interno y que, a la vez, pueda trascender dichas estructuras coloniales y neocoloniales que ejercen, en el seno de su humanidad, una negación práctica y ontológica.

Será el hombre latinoamericano el que puede y debe autodenominarse como sujeto. La identidad como problema es heredado de la tradición eurocéntrica y no es intrínseco al estatus existencial y ontológico de América, a la vez, desde aquí se puede practicar una trans-ontología respecto a la "unidad" opresora del eurocentrismo. Es un problema, también que hunde sus raíces en el tema de la diversidad cultural negada por este eurocentrismo a lo largo de toda la historia colonial. Por lo tanto, no solo atañe a un problema de identidad latinoamericana, sino mundial. Se reacciona ante la diversidad desde la mismidad de la comprensión de la unidad ontológica, univoca y cerrada. Desde este ángulo epistémico no se considerará a la diversidad cultural, espiritual, filosófica como un don, como una maravilla de la expresión de la vida, ni como posibilidad de ejercer acciones conjuntas múltiples, sino como un problema, como un caos a resolver.

El problema de la unidad e identidad en América Latina, bajo este proceso de dominación, ha sido siempre un dramático dilema. En este sentido es que Roig ha hablado de unidad referencial, sería un intento en marcha, aunque selectivo y con referencia a la diversidad y no como absoluto o a-histórico. Es un proceso de historización, también de incorporación por colonización, aculturación y destrucción de América al proceso colonizador europeo. Por otro lado, tenemos la visión de unidad de América concebida por los colonizadores e impuesta a los colonizados. Las élites, aristocracias, oligarquías seguidas de burguesías han ido desplegando diferentes horizontes de comprensión en la historia de los modos de unidad.

Hacia el Siglo XVI y XVII el continente fue denominado por los conquistadores como indias occidentales, nuevo mundo, nuevo orbe, América sería lo otro negado por el imperio español y portugués. Hacia el Siglo XVIII, se generalizó el nombre América refiriéndose a la América española y a la América portuguesa. En el Siglo XIX bajo influencia francesa y norteamericana se generaliza el nombre América Latina. Hacia el Siglo XX se conjugaron otros nombres como Hispanoamérica, Indoamérica, Euroamérica, Eurindia, Panamérica. Lo que comienza siendo un proceso de incorporación a lo europeo y termina en cruentos 
enfrentamientos, aunque no siempre fueron enfrentamientos, sino que también se llevó a cabo una sumisión a través de otros medios más sutiles como el legal. Hacia el Siglo XXI se generalizó América Latina entra en disputa con el término propuesto de Abya Yala de los indígenas Kunas (Colombia, Ecuador, Panamá) parte negada de la historia.

El criollo es el que hegemonizará este proceso de las formas de democracia. Y Roig parte de este sujeto de 1810 respondiendo a una visión criollocéntrica, sin considerar adecuadamente al sujeto indígena y a la Revolución Haitiana. América Latina es un ente histórico cultural porque se encuentra inmerso en un proceso cambiante de diversificación. Podemos decir también que en relación a una cierta realidad substante referente a diferentes unidades y diversidades que difieren de lo propiamente europeo. Aunque sea una distinción falsa las categorías de Viejo Mundo y Nuevo Mundo, de todos modos, han ejercido una fuerte influencia.

Debemos hacer desde Roig una revisión del concepto de nosotros a través de diferentes referentes propios y extraños de nuestra historia. El nosotros en Juan Bautista Alberdi incurre en un exceso de americanismo entendiendo por el mismo un derecho que solo el europeo tiene para invocar a América y no así el salvaje. Bajo esta lógica Alberdi apoyó la invasión Francesa en México. Para él es bárbaro y salvaje todo lo que no es europeo. Entonces el nosotros se reduce a un nosotros los europeos latinos de América, con ello los intelectuales, los inmigrantes de las aristocracias de origen español y, agregamos, portugués para el mundo lusitano.

Por otro lado, Bilbao desde una concepción diferenciada de un nosotros se oponía a los EE.UU como al latinismo francés. Para él, México no sería un espacio barbarizado, carente de diversidad y americanismo, sino lo más bello y rico de América. Su destino político no es la monarquía o su sustituto la República Aristocrática, sino la democracia que tiene en el pueblo mismo sus raíces. El olvido de estas raíces es causa del exterminio de este nosotros. Se olvida la amplitud de esta realidad y por lo tanto la libertad de todos/as adviniendo como conciencia de ese olvido, la violencia física e institucional. Este nosotros los latinoamericanos se diferencian de la América Sajona, aunque por otro lado reconozca que somos todos americanos. El nosotros de Bilbao está claramente identificado con el mestizaje que rastrea hábitos de vida no identificados totalmente con los hábitos de vida europeos. Para nutrir y fortalecer esta perspectiva se trata de un punto muy importante en Roig, que es de ponernos a nosotros mismos como valiosos, no en cuanto cosas, sino como sujeto de nuestra historia ${ }^{3}$, y por medio de ser y

\footnotetext{
${ }^{3}$ El sujeto colonizador se impuso como sujeto de la historia universal y a todo el resto los colocó como objeto de dicha historia. Todo esto es lo que estamos de-construyendo y descolonizando para el reconocimiento de la diversidad subjetiva, cultural, para la autonomía y la justa relación de los diferentes procesos históricos.
} 
tener identidad y unidad posible, lo que incluye solo a posteriori una disposición con el horizonte o mundo de los útiles.

En el nosotros Martí se pregunta ¿cómo llegar a lo nuestro? Y sostiene que supone la revisión de la actitud aldeana que lleva a razonar y reflexionar sobre nosotros mismos. ¿Por qué? Porque el punto de partida no es una reducida parcela, sino la diversidad que para Martí es lo que es. Otro punto de partida es la unidad que es paralela a la anterior, no es extraña a lo que es. Ahí es preciso una investigación de la propia referencia y los propios artificios de la razón. En la relación opresor-oprimido no se trata de conciliar para Martí, sino de ponerse por encima de la relación siguiendo la vía de colocarse al lado del hombre natural. Es la forma auténtica de hermanar al fin la diversidad incluso la del par antagónico.

Por otro lado, el nosotros en el caso de Carlos Octavio Bunge destaca las diferencias raciales psicológicas, el mestizaje del que habrá de surgir el genio hispanoamericano. El mestizaje tiene en su visión un encuadre hegemónico, dominador. Lo nuestro para Bunge tiene una doble perspectiva. Por un lado, es un presente, un ser dado como diversidad caótica. Y por otro lado, es un proyecto que radica en el "secreto" de la raza fuerte. ¿De dónde se extrae este elemento? El secreto de la historia se encuentra en la geografía, el genoma humano racial diferenciado entre fuertes-débiles es la fórmula creada en el mestizaje positivo en el que se logra que predomine lo castizo (razas y sub-razas) dominadoras. Para Bunge la violencia en cambio, no es un obstáculo, sino que es un recurso para vencer los impedimentos, así no se excluye el genocidio, estaría legitimado venido el caso. Para él los indios son más salvajes que los marinos europeos y los mulatos son monstruos apocalípticos. Sobre ellos se debe cernir todo el peso de la civilización.

\section{Horacio Cerutti Guldberg y la indagación sobre la metodología de la historia de las ideas de América Latina ${ }^{4}$}

En primera instancia, al abordar este tema es necesario aclarar que hay una intención pedagógica explícita consistente en intensificar el estudio de nuestras tradiciones filosóficas. Es fundamental multiplicar los proyectos, los programas, las disciplinas, los trabajos de campo, etc., dentro del ámbito de estudios latinoamericanos para cobrar mayor presencia e intensificar la senso-conciencia (C. Bauer, 2016). Para Guldberg la epistemología es el estudio de los modos de producción del conocimiento. Este punto es importante, ya que embebido de una influencia marxista, es posible abrirse a la diversidad en la producción del conocimiento filosófico.

\footnotetext{
${ }^{4}$ Horacio Cerutti Guldberg es un filósofo argentino nacido en Mendoza y graduado en la Universidad Nacional de Cuyo, perteneciente en un principio a la filosofía de la liberación, y luego es parte destacada de la historia de las ideas en su corriente problematizadora.
} 
Desde esta perspectiva se puede afirmar que la filosofía proporciona algún tipo de conocimiento de sí misma y de la realidad en la que surge, pero también se puede cuestionar el supuesto eurocéntrico de que la filosofía es la ciencia privilegiada por excelencia y en donde radican las verdades. Se trata de una visión opuesta al modelo Kantiano respecto a la condición a priori del conocimiento. Guldberg, en cambio, se inclina a afirmar las condiciones a posteriori, porque se parte de la experiencia, por eso la respuesta la encontramos después. La experiencia, por ejemplo, histórica para América Latina es fundamental para sus estructuras ontológicas y trans-ontológicas. La experiencia es un término modal. Esto en muy importante ya que va a determinar la posibilidad de que surjan diferentes modos, y en este caso lo que podemos, tal vez, llamar como modo latinoamericano de conocimiento. América tiene una experiencia distinta y no puede ser totalizada por la filosofía europea.

Entonces, la metodología dentro de este contexto mayor no puede ser una sola, unívoca, o un marco teórico para aplicarlo a la realidad, sea cual fuere el fenómeno que estudia la filosofía, el mismo se entronca con la historia y con la política. Se debe ubicar su relación entre la persona y el ente cultural como dimensión compleja y relacional, no como un a priori. En este caso se trata de una reconstrucción racionalista sistematizada a posteriori de los pasos y caminos que efectivamente se ha recorrido en la producción de la filosofía Latinoamericana. En este apartado, desde mi interpretación, lo que podemos llamar filo-sociohistoria es la que va a distinguir entre filosofía y filosofar. El filosofar es una acción práctica que parte de la experiencia y, a la vez que puede valerse de la filosofía tradicional también puede y debe deconstruirla en sus cierres absolutos. Por otro lado, en lo que hace al sujeto de este filosofar hay que afirmar que no hay algo así como un pueblo incontaminado que exista y se reproduzca fuera del sistema, en la exterioridad. Guldberg está discutiendo aquí con la tradición analéctica-ética del pensamiento latinoamericano en la versión de Dussel. Guldberg confunde aquí el concepto de exterioridad referido a una especie de sustancia externa al sistema, por ejemplo, de tipo levinaciana, pero Dussel no habla en este sentido, podemos decir de manera ligera, que exterioridad se trata de una metáfora para indicar lo que fue excluido por el sistema y conservar de alguna manera esa condición permanente de explotación como exterior o estar fuera de los beneficios, no tenido en cuenta de manera alguna para la economía política, por lo que para la historia, en sentido de resiliencia, será siempre un residuo y elemento marginal en potencia subversiva al interior del sistema mismo.

La filosofía debe ser producto de un ejercicio de producción teórica que lleva a filosofar de manera práctica. En el proceso de producción, al filosofar se lo concibe como actividad y no 
como idealización, o mero desarrollo de la idea, es un proceso siempre abierto y vivo, es un proceso de aquí. Concepto de investigación entendido como proceso de producción de nuevos conocimientos del filosofar y de la realidad (socio-histórica). Nos preocupa la filosofía porque nos preocupa la realidad. El pensar se modifica y esa es una de sus características principales, lejos de una sustancia inmutable, el pensar la realidad es ello mismo un objeto pero hay que afrontarlo como socio-histórico. Pensar la realidad no es un acto inmediato, sino que está mediado por múltiples factores: institucionales, ideológicos, materiales, históricos, epistémicos, mediación del lenguaje, del inconsciente, de intereses de clases, así como otros diversos problemas del estudio de la realidad.

Para Guldberg no ha sido una preocupación de la filosofía latinoamericana pensar en sistemas y nunca lo fue. Sí en cambio para establecer tópicos, por ejemplo, en primer lugar con ideas encarnadas y producidas por sujetos en determinadas condiciones históricas como sustento de argumentos a problemas socio-históricos. Esto enfrenta a la filosofía en sentido tradicional y conceptual. Para Guldberg el ser social determina la conciencia social y sus conceptos y no a la inversa. En esto no solo lo es para la historia de la ideas, sino para esta interpretación de la filosofía de la liberación, se trata de rescatar a la ciencia para que sea patrimonio de la humanidad. En segundo lugar, la filosofía sin más como: a) salidas y soluciones como producto-productor, vivo-abierto y socio-histórico, etc.; b) con características, por un lado como parte de la doxa (no alejado del mundo del trabajo), acepta la distinción doxaepisteme; c) propiciando respuestas a una realidad condicionada de la que se parte; y d) no es ajena a la ideología y se identifica con este como pensamiento para la acción, para la crítica cotidiana proponiendo algo. Podemos decir que todo esto está a tono con lo planteado por I. Ellacuría cuando se refiere a la ideología como cosmovisión, como una construcción acompañada de la función crítica y liberadora de la filosofía. Y en tercer lugar, Guldberg alude a los sofistas como estando presentes en los ejercicios simples para la población, y no asî desarrollando epistemes de élites, e ahí lo democratizante de los sofistas. Entonces el demos tiene al alcance la crítica.

\section{Günter Rodolfo Kusch investigando sobre una antropología filosófica americana ${ }^{5}$}

Veremos algunos puntos que han sido de relevancia en esta indagación de Kusch en la que se ocupa de una fenomenología de la afirmación. Por ejemplo, Grund significa, algo es pensamiento, acto de concesión o condensación, determinando un campo de objetos como área

\footnotetext{
${ }^{5}$ Günter Rodolfo Kusch fue un filósofo argentino nacido en Buenos Aires perteneciente a la corriente filosofía de la liberación desde la óptica de las culturas indígenas a las que llamó lo profundo de América.
} 
de clasificación. La objetividad como modo de pensamiento, la claridad, el área de coherencia, y desde este aspecto hasta qué punto la coherencia se da. Desde este ángulo necesito afirmarme a mismo para referirme a una proposición afirmativa, es decir, adecuar el pensamiento a la cosa.

La fórmula explícita sería me afirmo afirmando, siguiendo la secuencia causa/efecto. La determinación filosófica, la claridad, qué es circunstancial con objeto y precisión. El antidiscurso, entonces, significaría por otro lado abrirse a lo indeterminado, es decir a lo $A b$-Grund que para Kusch significaría, algo está como indeterminación filosófica y simbólica. Sería un qué sin objeto como plantea en el tomo III de las Obras Completas. Lo que puede tornar ambiguo dicho procedimiento y la relación con la vida. Pero dicha ambigüedad es la que abre a lo indeterminado y no controlado por el sujeto, aún más como un animarse a vivir. ¿Qué es lo más profundo y qué es lo circunstancial que se logra captar? El fundamento no se logra aprehender, mal que le pese a la tradición eurocéntrica, dicho fundamento se esconde y se diluye en lo impensable y en lo indefinido. No es intimidante porque carece de objeto, sino que por no ser circunstancial se repite. Y podemos decir que al repetirse convierte lo que se afirma en un juego frustrante. El "es" se disuelve en el estar y eso ocurre porque recupero la diversidad. El símbolo como intermediario entre la realidad y la alteridad invierte la dirección de mi afirmación. Pero si hay vacío es porque está y si está es porque hay vacío.

Analizar el estar es ambiguo pero esa ambigüedad es la que posibilita mantener los canales de la senso-conciencia abiertos, acompañando la dinámica de la vida y aceptándola en su gravidez. En cambio Heidegger excluye el estar del lenguaje filosófico, justamente lo hace por su ambigüedad. De todos modos la vida en Kusch no se define, sino que se transita entre el estar y el es. El estar en Kusch funciona como la vida, la cual también se desempeña como símbolo. La misma por un lado, se refiere a la no vida como acabamiento y como un estado especial que se llama muerte; y por otro lado, habiendo un antes, es decir, una instalación de la alienidad. Es un regreso a la alienidad que da la vida e incluso la muerte. Dicha vida transita un área que va de lo impensable a lo pensable donde se desenvuelve el pensamiento práctico. Abarca lo que va desde lo desalbergador del simple estar hasta su concreción en los circuitos de acción arquetípicos, que satisfacen el hambre y cumplen con una economía cotidiana de amparo con la lógica colectiva e individual de ganarse la vida salvándose de lo inestable que atenta contra dicha vida.

El trueque en la comunidad quechua, es un circuito de acción arquetípico y a la vez un símbolo que cumple, desde un saber vivir, con la satisfacción del hambre, y no apuntando a espurios intereses mercantiles que sacien el ego de bienes materiales. Este proceso diferente 
como sucede con la economía capitalista, está asistido por lo absoluto en una concurrencia tácita y social con lo otro como rector ambiguo de vivir. Se trata del misterio de la así llamada subjetividad pero en tanto está dada o está, frente a lo cual no puede ser referida a las cosas para lograr su definición. El "me" del me afirmo se refiere a una subjetividad y esta es la puerta que abre al misterio. Está en la antesala de las cosas. Hay cierta alteridad, el acto de afirmar no es totalmente mío, abre a lo impensado, es decir a una dimensión pre-óntica. Es evidente que el término vida como símbolo popular concilia la oposición entre el "es" determinante, afirmativo y el "me" afirmo que nos había internado en lo impensable del estar, o sea en lo pre-óntico, es el sentido de que pudiera tratarse de otro ontos en virtud de la presión que ejerce lo otro.

\section{El estar y el estar-siendo como categorías pedagógicas descoloniales}

El estar-siendo es propuesto por Kusch como estructura existencial de América y como decisión cultural americana. El estar es el que nos marca la distinción, es un pre-recinto o hueco pre-ontológico, y hasta pre-filosófico, puedo agregar, frente al sentido tradicional, pero filosófico al fin cuando se trata de reconocer otra dimensión de sabiduría posible con sus oscuridades y sus luces. Implica desde aquí no la reflexión de un ser constituido, sino sobre la previa experiencia originadora del ser, es reconocer una combinatoria y una operatividad básica y propia del sujeto americano como particular frente al fondo insondable y tenebroso del estar como campo siempre abierto y vivo.

Una comunidad que posibilita el filosofar y el vivir es una comunidad portentosa. Muy difícil y casi imposible de engañar. Una comunidad que considera el estar se mueve en una polarización en donde ser-nada son dos momentos equivalentes aunque abstractos. La nada es negatividad que participa del es. Se relega lo negativo a un problema de astucia de la razón. No se trata de la negatividad en general, sino de una negatividad reducida en su aspecto que la vincula con el ser. El sujeto del cogito del ego es el sujeto constituido por la presión de lo racional. Pero desde el sujeto des-constituido lo negativo ya no es un simple llegar a ser otro como lo equivalente. Ahí no hay equivalencia entre lo negativo y lo positivo, sino la quebradura racional, área de la sorpresa de la afección de la alternancia entre oposiciones, lo radical no es llegar a ser otro como desconstitución sin continuidad, sino con la asunción de lo absoluto y como sorpresa en la circunstancia. Se pasa del área donde se postula el ser al área del estar. Es ubicarse más allá y también más acá de la realidad como ser-ego. Es un estar sin más, desconstituido pero con una constancia sólida en la vida.

El reconocimiento del estar al margen del ser implica un saber de algo y un darse en este estar, al margen del cogito del ego, en medio de la quebradura racional que trasciende el pensar 
hacia la radical negatividad. En lo inmediato se conmueve toda constitución; se plantea así la total desconstitución del ego-sujeto; por eso al sujeto americano no le va el ser en su ser, sino en su modo de estar. Lo circunstancial del estar sustituye el imperio racional por el imperio de la negación. El diálogo (dialéctica) es el enfrentamiento con la negatividad, esfuerzo por encontrar un logos salvador sobre la quebradura de la razón poseída por la negatividad, por ejemplo, adivinación (forma de diálogo) con esta se dan respuestas desde un sentido cubierto más allá de lo negativo. No hay más astucia de la razón que cubrir esta quebradura, con la presencia de la negatividad y por consiguiente el diálogo con ella en requerimiento de lo absoluto.

Al fondo del acontecer se tantea el absoluto como condición de que haya sentido, es instancia dialéctica radicalizada como diálogo con la negatividad en requerimiento de una condición absoluta (un ardid litúrgico) logrando eficacia frente a una negatividad radical. Ante tamañas dimensiones solo cabe la magia, y recurrir a verdades seminales. La seminalidad propia de un pensar popular y de un pensar en general, se caracteriza por no seguir los criterios del pensamiento causal y se asimila a un pensar simbólico que supera las contradicciones en nombre de un puro vivir. Por eso el sujeto se da en el ámbito del cómo hacer, no del que es, se constituye por medio de la ceremonia y lejanamente a través de una ética, no quiere decir que el concepto ser se degrade como problemática, en tanto se refiere a lo absoluto, se traslada desde el lugar inmanente que le corresponde en el código filosófico, a un lugar ambiguo que media entre lo que es y esta. Aquí se abre lo sapiencial, que implica una forma de astucia radicalizada y por eso una liturgia justificable sólo mediante el pensar simbólico.

El símbolo es el ardid que transita a la palabra desde la in-mediable negación para regresar al estar. El discurrir simbólico se ubica en el ambiguo filosofar, entre el algo que es como constitución y el algo que esta como acontecimiento, por ello no hay texto, debería decir escrito (texto $=$ tejido) y aunque no haya escrito hay tejido de fondo y superficie. No hay escrito sin tejido pero hay tejido sin escrito. Es el tejido que evapora el ser yo-mundo (fórmula occidental de Husserl). Otro punto de partida es yo-trascendencia, teniendo parecer entonces con el viejo punto de vista ya no filosófico, sino sapiencial. El ser en el mundo lo sustituye por otro a priori no desarrollado por ellos que es "estar en la trascendencia", así nos ubicamos en un nivel anterior al de la evolución cultural en que se coloca Heidegger con sus estructuras de emplazamiento (Ge-stell) del ser. Desde el estar surge el diálogo que posibilita la "mediación simbólica”. De ahí lo sapiencial, pensar algo más que el mundo. Mundo es trascendencia antes que utensillo o, mejor es utensillo sometido a una trascendencia. El aspecto revolucionario es 
que se recupera la dimensión del espíritu de la cosmovisión indígena y se lo integra a la historia de la filosofía pluriversal y para el diálogo intercultural, de saberes y haceres.

El punto de arranque es el estar como fuerza que se refiere al esquema yo- trascendencia y el ardid litúrgico para superar en términos absolutos la negatividad destructiva. El siendo en cambio indica la curvatura del ser, no una posibilidad de ser. Entonces se trata de un estarsiendo que en realidad está, más que es, pero un es, siendo en relación a un estar que lo curvará siempre que sea necesario en función de la vida y no del sujeto-ego. Es diferente del Dasein que mide en razón del $D a$ lo que puede ser algo en el drama mediable de la caída del ser, pero no del vivir. En el estar no se da la continuidad de un pensar filosófico, sino la quebradura de la razón. En realidad con el cambio de paradigma se sustituye el ser-ahí por el estar-siendo, desaparece la concesión al ser por radicar la cuestión en el estar. El ardid metafísico de calificar lo negativo como una diferencia. El ardid logra mediar. La ontología en cambio divide, sólo pone la diferencia. Con el ardid caemos fuera de la ontología. Se trata del ardid de lo sapiencial. Se repararía en la descolocación de la ciencia ya que se volvería a cubrir dentro de un universo general. Contra la secuencia científica Kusch nos habla del riesgo de la causalidad, pero junto a este drama racional se ubica la astucia y esta aparece como una trampa hecha a la ciencia, que a su vez se constituye, supuestamente, para que no haya trampas. Pero desde el ardid sapiencial desde donde se puede des-armar dichas secuencias, se regresa al verdadero punto de conjugación entre el ser y el tiempo, pero era necesario recurrir al tiempo, porque detrás del tiempo está el movimiento de constitución que ocurre en cualquier tiempo, o mejor, fuera del tiempo. Lo ontológico, entonces, es un episodio y no el bloque de existencia.

\section{Juan Carlos Scannone y la propuesta de su nuevo punto de partida en la Filosofía Latinoamericana $^{6}$}

J. C. Scannone propone partir de la sabiduría popular latinoamericana, por la que considera el nosotros como equivalente al concepto pueblo. No termina en un resultado ni en un sistema estático ni en una dialéctica, sino en una abierta circularidad vivificante. Entonces podemos decir que para Scannone la filosofía como ciencia se torna equivalente a la filosofía como sabiduría popular latinoamericana. Si no tiene incorporada la sabiduría popular no sería considerada ciencia. Es una fuerte apuesta esta perspectiva descolonizadora, porque desde el punto de vista del paradigma moderno eurocéntrico nada relacionado a lo popular es considerado ciencia.

\footnotetext{
${ }^{6}$ Juan Carlos Scannone es un teólogo argentino nacido en Buenos Aires, es padre jesuita y pertenece a la teología de la liberación y filosofía de la liberación.
} 
Entonces ¿como se accede a dicha ciencia? Para Scannone se accede a través de la mediación pero no intermediaria, ni dialéctica, sino analéctica. En la mediación analéctica interjuegan, por un lado, la mediación simbólica; por otro, la analógica; y en último término la éticahistórica. Las categorías fundacionales de esta nueva filosofía son las de estar, nosotros, mediación simbólica y analógica. Y entre ambas puede darse una intermediación, una circumincesión que marque una dinámica propia.

Por su lado, Raimon Panikkar habla de la intuición cosmo-teándrica que admite el triple juego de inter-independencia de la trascendencia de la realidad divina, humana y cósmica en una perichôrêsis no determinada, que es lo libre. Funciona como imperativo intercultural que acepta la diferencia. Entre las tres, como expresión y forma de una filosofía que piensa especulativamente a partir de la sabiduría (logos sapiencial, simbólica, ético-histórica) popular y en vivificante tensión con ella. Es interesante trabajar también aquí con la noción de ideología como la aborda Ignacio Ellacuría. Para él la ideología es una cosmovisión en función liberadora, mientras que la ideologización es una falsación de dicha perspectiva. Por lo tanto lo propuesto por Scannone dentro de la filosofía de la liberación puede ser interpretado como ideología en sentido de Ellacuría, es decir, como cosmovisión o visión de mundo. Un nuevo punto de partida en la Filosofía Latinoamericana debe considerar estos aspectos de la visión de Scannone. Otro de los puntos centrales es el mestizaje cultural que debe estar apuntalado por las categorías propuestas, algunas de ellas mestizas por excelencia como la de nosotros y la de pueblo. El pueblo nиеvo es resultado del mestizaje entre aborígenes, europeos y africanos. El concepto de estar es el que posibilita, como instancia previa, o espacio de libertad que se abre como posibilidad de conjugar diferentes elementos culturales y filosóficos para poder conformar un proceso identitario propio y auténtico. En esta concepción debemos precisar la visión teológica de Scannone un poco más adelante. Veamos según Scannone algunos aportes a lo humano universal desde los informes de Medellín ${ }^{7}$ y Puebla ${ }^{8}$.

\footnotetext{
${ }^{7}$ La Segunda Conferencia General del Episcopado Latinoamericano fue llevada a cabo en Medellín, Colombia, del 24 de Agosto al 6 de setiembre de 1968. Dicho acontecimiento fue convocado por el Papa Pablo VI para aplicar las enseñanzas decididas en el Concilio Vaticano II a las necesidades de la Iglesia en América Latina, con la temática propuesta "La Iglesia en la presente transformación de América Latina a la luz del Concilio Vaticano II". La apertura de dicho evento estuvo cargo del Papa, marcando el hecho histórico en el que por primera vez un pontífice visitaba América Latina. Entre todos los temas tratados fueron predominantes los referentes a la justicia, la paz, la pobreza y la liberación. El Concilio Vaticano II fue convocado por Juan XXIII el 25 de Diciembre de 1961, con la Bula Papal Humane Salutis. Realizado en cuatro sesiones que se extendieron hasta el momento del Papado de Pablo VI. Los motivos y objetivos del concilio fueron numerosos, pero podemos resumirlos a fines de esta nota, diciendo que se realizó un balance de la iglesia a fines de readaptarla a los nuevos tiempos presentes y futuros.

${ }^{8}$ La Tercera Conferencia General del Episcopado Latinoamericano se realizo en Puebla de los Ángeles, México, del 27 de enero al 13 de febrero de 1979. Paulo VI convocó oficialmente la III conferencia el 12 de diciembre de 1977 con el tema "Evangelización en el presente y futuro de América Latina", pero su fallecimiento y el breve
} 
En primer lugar, veamos la filosofía de la Liberación en el caso de Dussel según Scannone. Este es un filósofo versátil, multifacético y uno de los principales representantes de dicha filosofía. Nace en Argentina, Mendoza en 1971. Con el precedente teórico y fáctico de la teoría de la dependencia y de la teología de la liberación irá repensando su propuesta analéctica ética y política que no estará desprovista de un profundo y concreto pensamiento económico. Sus categorías transitarán el influjo de totalidad e infinito, así como los planteos metafísicos de influencia helénica, que profundizados desde la ética de Levinas y la económica de Marx darán la experiencia ética del otro develando el rostro del pobre como oprimido y empobrecido, lejos de ser considerado como una naturalidad ontológica. La filosofía de la liberación comprendía la alteridad y la trascendencia considerada ética y socialmente estructurada así como históricamente situada y no solo privada o intimante. Son los puntos nodales, versátiles y dinámicos que pueden deconstruir los procesos de dependencia apuntando a una liberación posible.

En segundo lugar, Scannone comprende a R. Kusch siendo precursor de la perspectiva hermenéutica histórico cultural como un reducto de la sabiduría popular del pensamiento filosófico que media entre la cultura, la religiosidad y los símbolos. La narrativa popular como sabiduría popular de contenido con sentidos últimos de la vida, con forma y racionalidad peculiar, así como la sapiencial consideración de las diferencias en las dinámicas propias de crear-recrear siempre conceptos populares que nominen y den consistencia senso-conciente a la identidad propia como una forma poderosa de relacionarse sin ningún tipo de desventaja con la filosofía académicamente elaborada. El pueblo como sujeto comunitario de una historia común es la referencia de raíz, puedo agregar, para co-pensar (P. Riviere) la propia realidad como colectiva y la filosofía que surge de esa experiencia. No se trata en este caso de una superación de la filosofía de la liberación, sino de un desarrollo con-junto con otras líneas que expresan otras experiencias.

En tercer lugar Scannone expone lo que es propio de su visión en relación a la teología, y la familiaridad con la propuesta de Carlos Cullen. Scannone muy en sintonía con la visión de Kusch, de Cullen y en discusión con Dussel considera de lleno que la sabiduría popular latinoamericana es un lugar hermenéutico. Trabaja también fuertemente influenciado por la fenomenología existencial de Ricoeur en su vía larga, es decir considerando una hermenéutica de los símbolos para adentrarse a las otras culturas oprimidas por la conquista. La vía corta de

pontificado de Juan Pablo I, hicieron que se postergara hasta la fecha indicada al comienzo de la nota. Será Juan Pablo II quien inaugure este evento marcando el hecho de ser la primera vez que este Papa visitaba América Latina. 
la descripción cultural histórica encuentra una dialéctica, en tanto diálogo entre ambas vías pero dentro del círculo hermenéutico de la sabiduría popular. Las categorías nosotros, estar, mediación simbólica, son tres horizontes de comprensión global y metafísicos culturales que posibilitan la comprensión de una realidad otra, auténtica y de carácter descolonizador. Se trata de una circularidad descolonizadora. Si consideramos a Descartes y su ego cogito es totalmente distinto del nosotros como una suma del estar y la cultura histórica propia. Se trata de ¿una nueva perspectiva filosófica? afirmamos que sí.

En ella se conjugan los horizontes del ser, del acontecer y del estar. Pero también podemos plantear el nuevo punto de partida como lo hace $\mathrm{C}$. Cullen, como un no absoluto con el concepto de Nosotros-estamos. Scannone propone cuatro conceptos para relacionarse con el nosotros-estamos, y los mismos son los de alteridad, misterio, gratuidad y novedad. De la fecundación mutua entre el logos griego y la fe cristiana en la creación gratuita nace la comprensión tomista de la analogía entis. Se trata de un ser diversificado por la fe cristiana popular, y no totalizado como acontece con la imposición de la iglesia conquistadora y dominadora.

Se trata de incorporar y no negar el elemento vivo de la fe popular dentro de la filosofía y de la realidad de la cultura. El horizonte del estar como un "nosotros estamos" es una experiencia inmediata que no puede ser totalmente medida ni cuantificada por la reflexión autoconsciente, sino que es opuesto al ego cogito (cartesiano) y al ser-en-el-mundo (Heideggeriano). Propone dos caminos para comprender el nosotros-estamos; por un lado seguir los pasos de una fenomenología de la sabiduría que allí encuentra su punto de partida. Y por otro, un camino más abstracto, analítico y apropiado para una nueva aproximación.

La reflexión fenomenológica del nosotros como sujeto-pueblo en su comprensión es opuesta a la de Hegel y Husserl. Se trata de un nosotros distinto al ego cogito y su autoconciencia, se trata de un sujeto comunitario constituido de manera previa, pre-ontológica, desde el estar, como posibilidad para ser y para que la historia acontezca de una manera diferenciada. Desde el pensar sapiencial y su simbolizar se puede articular este vasto campo. Este es el filosofar del que se parte. Para Scannone el nosotros-estamos comienza desde su primera experiencia que es la interrelación ético-religiosa situada en la experiencia de la cultura, y no desde la metafísica tradicional que distingue entre espíritu-materia, inteligible-sensible, universal-particular, sujeto-objeto como categorías en los que están comprometidos de manera exclusiva los procesos de universalización del Yo (ego ) como sujeto trascendental. El nosotrosestamos implica además del yo, el tú, los él, y supone el Él, los ellas, aunque Scannone no 
introduce este término, pero ninguno reductible entre sí ni mucho menos al Yo (ego) ni siquiera comprendido trascendentalmente.

Por eso la universalización propia del lenguaje hermenéutico del nosotros-estamos no se comprende como universal abstracto ni concreto al modo hegeliano, sino como universal situado. Para Scannone el primero en emplearlo de esta manera fue Mario Casalla, y en esto Scannone acuerda con él. La eticidad y la religión de la que habla Scannone implican un estar arraigado a la Tierra pero no de cualquier forma, sino como símbolo y realidad. La experiencia precaria del nosotros-estamos en la que se dan simultáneamente la relación persona-persona (el nosotros se prefigura como yo, tú, él) y la relación persona-Dios (el nos-Otros que implica el absolutamente Otro) y desde mi punto de vista la falsa relación poiética persona-naturaleza en la producción, cuando la naturaleza es tratada como objeto y mercancía, cuestión que cambia cuando la relación productiva es mediada por la cosmovisión-cosmovivencia de vida, y en este caso que estamos tratando, por una visión ético-religiosa que no cuantifica, sino que cualifica, hasta sacraliza todo el proceso. No prima aquí el modelo unívoco científico-técnico (epistêmêtechnê), sino el modelo plurívoco ético-religioso.

La analéctica del filosofar a partir del nosotros plantea la eticidad del saber como experiencia, no como mero constructo teórico. El logos y el saber no se reducen al ethos y viceversa. El sapere (saber) como metáfora de saber y sentir, no así tanto de la intuición intelectual eurocéntrica del ser. Para Scannone, como teólogo de la liberación, la relación ética es al mismo tiempo religiosa: 1) horizontalmente en cuanto al diálogo ético no solo como horizonte de un nosotros, sino además de este con otros nosotros; 2) verticalmente, en donde se pone en juego la parte fuerte de la analéctica en Scannone, como relación con Dios como momento que muestra la condición humana finita, y muestra otro momento trascendente que es intrínseco al nosotros ético y que lo desborda por dentro como su trasfondo último y por fuera como su juicio. De ahí el núcleo ético-mítico (Ricoeur) que en cuanto ético implica la relación horizontal a lo comunitario e inter-comunitario y en cuanto vertical con el absoluto que lo funda como relación ética.

La expresión y la forma ético-mítico nos abre al segundo sentido de lo religioso, en cuanto trasciende al nosotros-estamos hacia arriba como símbolo, está el cielo, y por abajo hacia el otro polo la Tierra en cuanto sagrada y madre tierra (dimensión atómica) en la que se arraiga y se acoge el nosotros. La experiencia es que nosotros estamos en la tierra. El nosotros-pueblo está en relación con la tierra en la que está, no es una relación meramente económica, sino primeramente religante (religiosa) y ético comunitaria-cultural desde donde lo económico se 
resemantiza y adquiere una función de vida y no de ganancia. No se puede reducir la physis a la naturaleza medida como sujeto-objeto. La relación ética-religiosa aparece como símbolo de lo numinoso, de lo sagrado, de lo ctónico, de lo materno de la religiosidad que no se reduce a lo ético, escatológico, uránico. Es símbolo del misterio de Dios, sin negar su trascendencia, sino afirmándola desde otro ángulo como centro del nosotros al que trasciende por dentro y como raíz misteriosa de su estar. La Pachamama se figura como verdadero simbolismo que apunta a ese aspecto del Absoluto. Para L. Boff se corresponde con la tercera persona de la trinidad. De todos modos en este horizonte ético-religioso se trata de un misterio raigal e indispensable. De esa manera es posible hablar de raigalidad (simbólica) y de trascendencia (ética) del saber (lógico) que implica la experiencia del nosotros estamos. Es similar a la visión cosmo-teándrica de R. Panikkar.

La ambivalencia de la sabiduría como momento lógico del núcleo ético-mítico de la cultura de un pueblo es la que funda su universalidad situada como horizonte de movilidad según lo percibo en esta dinámica. En el estar en la tierra radica una fuerza de resistencia a la alienación que constituye una primera afirmación de sí como nosotros y de su estar en esta tierra como cultura. Desde esta afirmación la resistencia indaga la negación (agresión-alienación contra la que resiste). Luego viene una afirmación segunda o eminente que trascenderá la mera negación de la negación. El nosotros se auto afirmará como resistencia, y como lo religante que es previo y que funda. Dependerá según creemos en su trasfondo metafísico del modo como se comprendan la unidad en la distinción, la mediación y la determinación lógica de la que hablamos más arriba. Cree que el actual pensamiento latinoamericano no ha respondido suficientemente a esta problemática. Pero al plantear el problema ya es una forma de abrir el horizonte de la respuesta.

Los caminos de construcción de respuestas, conjuntamente con las mediaciones simbólicas, crean un campo complejo en donde no todas las respuestas serán coincidentes con la nuestra entre sí exigiendo mayor esfuerzo de articulación. La identidad y la diferencia en relación y, a la vez, derivadas en tres dimensiones: 1) simbólicas numinosas; 2) ético dialogal y 3) cogito-sapiencial excluido del ego. Ni el reduccionismo, ni el dualismo son soluciones adecuadas. Las tres se dan en momentos distintos e irreductibles entre sí que pueden ser expresadas con la conjunción "y" como nombrando una totalidad que no subsume a la alteridad, sino que la deja ser y la respeta. Desde mi punto de vista es típico en la experiencia del nosotros en la que yo-tú-los-él-ellas forman comunidad sin reducirse mutuamente, y es lo típico de la 
experiencia del estamos, en la que el nosotros que está y el estar del nosotros en la tierra se unen analógicamente sin subsumirse el uno/a con el otro/a.

El nosotros-estamos es una experiencia ética y religiosa, no es exclusivamente lo uno ni lo otro. Parece dualidad pero es en realidad una trinidad, ya que es el hecho de una tercera dimensión que no sobra, sino que asume dialécticamente a las otras desde sí, sin reducirlas, al mismo tiempo que media entre ellas. Lo propio del símbolo que ya desde su etimología nos refiere a la unidad de los distintos. La tercera dimensión que se sustrae y su relación con la identidad del logos y la alteridad del ethos. Intentaremos explicar la mediación que en el símbolo se da, que acontece y que se sabe, tratando de pensarla según el símbolo mediador del símbolo. Sensiblemente hemos pasado del planteo de la unidad en la distinción, al de la mediación simbólica que la hace posible. La mediación que des-ambigua o determina sobre determinación del símbolo. Por ello el pueblo como sujeto histórico cultural se constituye fenomenológicamente y se sabe sapiencialmente el sentido de la vida solo a través de su núcleo cultural ético simbólico, articulado en un mundo de símbolos que se ponen dialógicamente en acción y sí van formando una tradición que articule científicamente el saber sapiencial.

La prioridad de orden, entre las tres dimensiones, 1) simbólico numinoso; 2) éticodialógico; 3) lógico-sapiencial; siendo que en el nivel fenomenológico de la experiencia del nosotros-estamos, la raigalidad se da en el estar, en el trasfondo semántico (ctómico y numinoso) del símbolo y del movimiento simbólico de creación y recreación de símbolos; el lugar mediador lo ocupa el nosotros (ético-religioso) que dialogalmente (vertical-horizontal) pone en juego el trasfondo irreductible de reserva inagotable de sentido, así se media y determina como término de ese movimiento el logos sapiencial que discierne, piensa y articula el saber al símbolo y desde el cual es posible nutrir desde las raíces sapienciales tanto a las ciencias como a la acción histórica, enraizando ser y acontecer en el estar.

\section{Raúl Fornet Betancourt y la transformación intercultural de la filosofía 9}

Aunque complementaria a las demás propuestas Fornet nos obliga, sino a cambiar el ángulo, sí a explicitar, focalizarnos y desarrollar un aspecto determinante. Para Fornet y su propuesta de transformación intercultural de la filosofía se trata de aprender a filosofar desde el contexto del diálogo de las culturas. Es no solo un impulsor teórico, sino práctico de dicho diálogo. Por ejemplo, en México del 6 al 10 de Marzo de 1995, se llevó a cabo el Primer Congreso Internacional de Filosofía Intercultural como lanzamiento de una plataforma

\footnotetext{
${ }^{9}$ Raúl Fornet Betancourt es un filósofo cubano, nacido en Holguín y perteneciente a la filosofía de la liberación, siendo uno de los principales iniciadores de la filosofía intercultural.
} 
internacional para el fomento de una nueva manera de filosofar cuya práctica debe influir en el horizonte de la filosofía tradicional comprendida, y ello para propiciar la realización de la transformación de la filosofía.

Es la posibilidad de rehacer la filosofía desde nuevas experiencias de inter-fecundación entre las distintas filosofías de la humanidad y que hoy exige el diálogo de las culturas, como mayor requisito para su efectivización. Es un programa de trabajo filosófico de largo aliento en el que ya hay importantes primeros pasos. En la fase social se trata de poner a la filosofía a la altura de las exigencias del diálogo de las culturas, sin malentendidos culturistas abstractos u ontologismos cerrados, opresivos o que obliguen a una conversión hacia su sí mismo. Por eso la transformación no es una meta en sí misma, sino para contribuir a un mundo que en la práctica pueda ser transformado interculturalmente y que desde ahí sea factible planificar de manera colorida, pluri-cromático, pluri-forme y pluri-sensorial. Se trata de una mejor filosofía para combatir la globalización que opera como civilización uniformadora y como único proyecto de la "humanidad" que no tolera diferencias culturales, ni siquiera como planos alternativos.

Por su lado, la globalización roba el eje estructural básico para cualquier desarrollo ulterior propio como derecho a determinar las formas de dominio sobre el propio tiempo y espacio cultural. El diálogo de culturas y sus saberes ancestrales se presentan como un horizonte alternativo, incluso de esperanza para el rostro actual del mundo y contra el huracán de la globalización como gusta expresar Franz Hinkelammert. La fuerza uniformadora del pensamiento único de la globalización es causa de un proceso sin precedente en la historia de la humanidad como imposición de una armadura global que aprisiona a la diversidad.

No hay que empezar por el diálogo, sino preparando las condiciones de posibilidad en la que el diálogo puede darse ${ }^{10}$, y como parte sustancial de esas condiciones exigir que el diálogo de las culturas sea de inicio un diálogo sobre los factores económicos, políticos y militares que condicionan el inter-culturalismo frecuente entre las culturas, lo cual es importante para no descontextualizar y no dejar de ver las asimetrías que hoy se multiplican, estableciendo las bases reales para las condiciones de igualdad.

La filosofía tiene en Fornet una función liberadora así como la definió Ellacuría, y explicitada de la siguiente manera para Fornet: 1) estimulado por Nietzsche es necesario desenmascarar las contradicciones fundamentales de la realidad socio-histórica; 2) inspirado en

\footnotetext{
${ }^{10}$ Iniciar directamente el diálogo presupone conocer al otro como otro que en realidad no conocemos. Hasta ahora hemos conocido lo otro desde nosotros mismos. Conocer al otro desde el otro es una condición previa que prepara la plataforma para que el diálogo intercultural sea posible. Las otras condiciones están dadas por la deconstrucción de los fundamentos cerrados y absolutos que nos constituyen, por una descolonización epistémica, ética, política, económica, estética, ecológica, espiritual que nos reducen y reducen a la alteridad y a la ecología como objeto, etc.
} 
Marx se trata de contribuir a definir las condiciones que reconocen y respetan el derecho de cada cultura a disponer de la completa materialidad, y de la economía para su libre desarrollo. El espacio material es fundamental para la práctica del derecho. Por ejemplo, ni más ni menos, derecho a tener mundo propio y reconocerlo. Aquí se juega parte fundamental del compromiso crítico que es denunciar dicha enajenación y alienación. También se trata de desarrollar una competencia para formular un plan para el desarrollo de la crítica y mostrar que el monoculturalismo uniformador también tiene un plan por excelencia desde donde lleva a cabo su homogenización de manera sistemática; 3) de propio cuño se trata de establecer un compromiso de la filosofía con la "cuestión previa" en las condiciones del diálogo de saberes y de culturas; 4) es fundamental la actitud creativa y recreativa para realizar los aportes necesarios, si se comprende que el compromiso con el diálogo es parte de su misma transformación intercultural.

La cooperación en la realización de la crítica incluye la misma tarea frente a la reconstrucción de su árbol genealógico, de sus conceptos y métodos. Puedo expresar que de esta forma se puede ver una existencia profunda frente a la uniformidad de la superficie. Para Fornet la cultura no es una esfera abstracta reservada a la acción de valores espirituales, sino el proceso concreto por el que una comunidad humana determinada organiza su materialidad en base a los fines y colores que quiere realizar. No hay una cultura sin materialidad organizada por fines, principios, valores, etc. En filosofía no se puede renunciar a los procesos de transformación, de lo contrario la filosofía se pudre y muere presa del estancamiento de las “esencias" cerradas. La Filosofía desde la inter-conversación a través del diálogo comunica lo propio y participa de lo diverso como base para universalizarse realmente, superando la etapa monológica de la anterior filosofía a manos de la inter-comunicación de las visiones del mundo.

La interculturalidad o práctica de la filosofía desde el contexto y las exigencias reales del diálogo de las culturas es una oportunidad para que la filosofía y las culturas logren una verdadera universalidad que hoy puede llamarse pluri-versidad. Se trata de una universalidad real construida por las distintas partes, no se trata de una descontextualización del pensamiento. La transformación intercultural no es un fin en sí mismo, y tampoco lo es la universalidad en la filosofía intercultural, si la busca es para apropiarse mejor de las diferencias culturales.

Las exigencias epistémicas y prácticas del diálogo de culturas marcan el ritmo de transformación de estas. La transformación intercultural se convierte en formato y estructura de transformación de las culturas en diálogo (dialéctica-analéctica) potenciando las posibilidades críticas que cada cultura posee para favorecer la desobediencia social, en analogía a la "desobediencia cultural" como una función importante de la filosofía intercultural. La 
interacción de las culturas y la originalidad que puede producirse de ello nace de procesos históricos, no caen del cielo, ni se generan en abstracto, son además procesos de fronteras epistémicas que, a su vez, pueden separar y unir, podemos decir analógicamente, universos culturales específicos, al mismo tiempo que en el territorio concreto se descubren y redescubren puentes que sirvan de canales de comunicación. En cada cultura hay una historia de lucha por la determinación de sus metas y valores que no son, sino una pluralidad de tradiciones que han atravesado procesos similares. Así es que en cada cultura debemos considerar sus tradiciones de liberación o de opresión, incluso frente a otra cultura que ha podido ser su opresora pero con la cual puede y hasta debe, por imperativo intercultural, iniciar un diálogo intercultural.

Incluso precisando la función de la filosofía intercultural, en cuanto a fomentar la "desobediencia cultural", debe decir que no solo se la plantea frente a la cultura hegemónica, sino también al interior de cada universo cultural específico. Este punto es muy importante a considerar debido a que una cultura en particular, así sea en situación de oprimida puede, y de hecho sucede, generar cierres opresivos institucionales que deben ser desobedecidos intraculturalmente para favorecer procesos de descolonización del saber y de transformación internos. Se trata de crear universos transitables, modificables al exterior y al interior de la cultura, rompiendo el estatismo anquilosado de la opresión y el burocratismo cultural. Se es conciente del pasado, pero también de un presente que puede ser de cambio, sobre un futuro no muy lejano en el que se puede refundar nuevos procesos de interacción.

La filosofía intercultural fomenta la "desobediencia cultural" mostrando que toda cultura tiene el derecho a ver el mundo desde sí, sin reducirlo a su noción como si fuera la única visión. Cada cultura tiene el derecho a interpelarse a sí misma y desde sí misma sin necesidad de tutela. La "desobediencia cultural" es pues praxis cultural de libración, así como la perspectiva de fondo desde donde cada persona puede hacer de su cultura propia una opción. El ser humano nace culturalmente situado pero esta situacionalidad no es un destino cerrado, sino un comienzo del camino. La situacionalidad cultural es dinámica y por eso desde ella se puede optar por otras alternativas. Podemos incluso recuperar tradiciones oprimidas dentro de la propia cultura, así como resumir y drenar la interacción de contradicciones con otras culturas, invirtiendo las perspectivas y abordándolas desde el horizonte de las anteriores.

La "desobediencia cultural" propone como necesario agudizar en cada cultura la conciencia de que sus sujetos deben retomar crítica y constantemente el conflicto de tradiciones que a su vez trata de ocultar la cara humanizada y estabilizada de la cultura. Todo ello es posible 
leerlo en clave de la dialéctica de liberación y opresión que parece ser la clave de resolución del conflicto entre tradiciones. Dicha dialéctica puede cumplir también con su función transformadora de tales contradicciones culturales, como una opción ética de resolución de conflictos en los que se respeten los diferentes universos culturales y se consolide una convivencia pluriversal. La "desobediencia cultural” es también actualización de las opciones éticas liberadoras con la que se puede y debe (imperativo ético de convivencia) operar para la resolución de conflictos y construcción de un nuevo campo.

Así liberación e interculturalidad se presentan como paradigmas complementarios y los instrumentos para realizar los diálogos entre las universalizaciones y pluri-versación de las culturas. Las identidades culturales son procesos conflictivos que deben pasar por múltiples procesos históricos y en la actualidad pueden ser cotejados a la luz de la interculturalidad. El multiculturalismo en una filosofía y política no convergente con la filosofía intercultural. Se trata de una sumisión y homogenización de la diversidad cultural dentro del sistema capitalista, sin respetar éticamente las diferentes cosmovisiones, ni económicamente los distintos modos de producción.

La función fomentadora de "desobediencia cultural" busca la transformación de las culturas por procesos de interacción, concibiendo las fronteras culturales no como límites, sino como líneas o puentes que conectan. La filosofía a la altura y nivel del diálogo de culturas posee un doble compromiso mutuo: por un lado, aprender a filosofar y reubicar nuestra filosofía desde el contexto del diálogo de las culturas y, por otro lado, conciliar esta filosofía como explícitamente transformadora en su carácter intercultural, transformando cada factor que atañe a las culturas en que nos movemos como un profundo momento de liberación y de esperanza para la actualidad del mundo.

\section{Conclusión}

A los fines de propiciar una educación descolonial, es importante considerar algunas de las propuestas conceptuales de los diferentes autores tratados en este texto. Partir del concepto de sujeto latinoamericano como lo propone A. A. Roig, que en el escrito lo acreciento como sujeto indígena, afroamericano, criollo-mestizo, ya que Roig se refiere sobre todo al criollo, nos proporciona un punto de partida desde un horizonte histórico propio que nos remonta a la construcción de nuestras identidades, que bajo la visión epistémica eurocéntrica no es posible ya que las mismas son negadas y destruidas desde la negación de sus propio horizonte histórico y la imposición de una historia ajena. Reconociendo la propia historia y los diferentes sujetos histórico con sus filosofías articuladas se puede construir tipos de unidades reales diferentes a 
las impuestas por los sujetos hegemónicos que excluyen a la mayoría del pueblo latinoamericano.

Desde esta óptica es interesante aplicar el concepto de epistemología de H. C. Guldberg, cuando define a la misma con un carácter práctico y no esencialista, siendo en este caso modos de producción del conocimiento. Dichos modos de producción pueden articular las diferentes epistemes de los diferentes sujetos, orientándolos con un sentido práctico y descolonizador en dicho horizonte histórico ya reconocido, resolviendo los problemas de unidad social con fines a poder construir proyectos conjuntos y articulados para la resolución de los problemas del mundo de la vida.

Este proceso epistémico e histórico puede ser profundizado desde los aportes de G. R. Kusch cuando plantea la construcción de una antropología filosófica que dé cuenta de la conformación subjetiva del propio sujeto latinoamericano. El estar es una de estas categorías que va a descolonizar el concepto de ser-ego en su unidimensionalidad capitalista, colonizadora y destructora. Por otro lado el concepto de estar-siendo es para Kusch también propio de América, ya que reconoce el proceso histórico y la influencia de occidente, pero se va a tratar de un ser ya fagocitado en el estar y reorientado dramáticamente con base en el estar y no dislocado de una realidad mayor que anteriormente era solo negada.

Desde los aportes de J. C. Scannone podemos visualizar el conjunto social ya que este teólogo plantea, contra el modelo de ciencia y filosofía hegemónico, partir desde la sabiduría popular latinoamericana, por lo que considera al estar como un nosotros equivalente al concepto de pueblo. En esta nueva posición del nosotros-estamos en la tierra en el que se implica el yo, tú, los él, ellas, Él, es necesario co-pensar para co-actuar y no pensar por todos ni actuar en nombre de todos. La diversidad constituye un nuevo momento del pensar y del actuar en donde se deben conformar dichos nuevos proyectos articulando las diferentes voces éticas.

Este proyecto diverso se puede apreciar explícitamente y con claridad desde la propuesta de R. F. Betancourt con la transformación intercultural de la filosofía que hasta ahora había sido mono-cultural en su versión eurocéntrica. Rehaciendo la filosofía de esta manera, desde las nuevas experiencias de inter-fecundación se pueden conformar proyectos interculturales más sólidos y sustentables desde la óptica ecológica, espiritual, cultural, ética, histórica, política, económica, estética. El proyecto intercultural no tiene solo implicado cuestiones teóricas, sino fundamentalmente cuestiones prácticas en donde se promueve un mundo y una humanidad transformadas interculturalmente, en donde los otros ya no son meros objetos, sino fuentes de vida para un nuevo mundo. 


\section{BIBLIOGRAFÍA}

Ardiles, Osvaldo; Assmann, Hugo; Casalla, Mario y otros: Hacia una Filosofía de la Liberación latinoamericana. Buenos Aires. Editorial Bonum. 1974.

Ardiles, Osvaldo; Casalla, Mario; Chaparro, Máximo y otros: Cultura Popular y Filosofía de la Liberación. Buenos Aires. Editorial Fernando García Cambeiro. 1975.

Bauer, Carlos: “Acerca de Guldberg...”. Córdoba. Revista La Vigía No 2, 2007.

Bauer, Carlos: "Necesidad-contingencia en la antropología social y cultural y descolonización de la economía política", en La construcción discursiva de la identidad: la emergencia de la voz indígena. Córdoba. Colección Sentido y Performatividad, UNRC, 2011.

Bauer, Carlos: "El vuelo del colibrí. América honda. América entrecultural. Superación interior del capital. Vademécum de una filosofía orbital”. Goiânia. Editorial Phillos. 2019.

Bauer, Carlos: Analéctica latinoamericana. Un pensamiento descolonizador para el siglo XXI. Buenos Aires. Editorial Prometeo. 2019.

Betancourt, Raúl Fornet: Transformación intercultural de la filosofía. Ejercicios teóricos y prácticos de filosofía intercultural desde Latinoamérica al contexto de la globalización. Bilbao. Editorial Descleé de Brouwer. 2001.

Boff, Leonardo: Teología del cautiverio y de la liberación. Madrid. Ediciones Paulinas. 1980.

Cerutti Guldberg, Horacio: Para una metodología de la historia de las ideas (filosóficas) de América Latina. Universidad de Guadalajara. 1986.

Fanon, Franz: Sociología de la Liberación. Buenos Aires. Ediciones Testimonios. 1970.

Hegel, Georg: Lecciones sobre la filosofía de la historia universal. Madrid. Editorial Alianza. 1997.

Kant, Immanuel: Crítica de la Razón Pura. Estética trascendental. Buenos Aires. Editorial Losada. 1957.

Kant, Immanuel: La paz perpetua. Madrid. Editorial Espasa Calpe. 1982.

Kant, Immanuel: La religión dentro de los límites de la mera razón. Madrid. Editorial Alianza, 1995.

Kusch, Günter Rodolfo. Obras completas. Tomo I, II, III, IV. Rosario. Editorial Fundación Ross. 2000.

Roig, Arturo Andrés: Teoría y critica del Pensamiento Latinoamericano. México. Editorial Fondo de Cultura Económica. 1981.

Scannone, Juan Carlos: Nuevo punto de partida en la Filosofía Latinoamericana. Buenos Aires. Editorial Guadalupe. 1990. 